\title{
Assessing the Evolution of Soil Moisture and Vegetation Conditions during a Flash Drought-Flash Recovery Sequence over the South-Central United States
}

\author{
JASON A. OTKIn, ${ }^{\mathrm{a}}$ YAFANG ZHONG, ${ }^{\mathrm{a}}$ ERIC D. Hunt, ${ }^{\mathrm{b}}$ JeFF BASARA, ${ }^{\mathrm{c}}$ MARK SVOBOda, ${ }^{\mathrm{d}}$ \\ MARTHA C. ANDERSON, ${ }^{\mathrm{e}}$ AND CHRISTOPHER HAIN ${ }^{\mathrm{f}}$ \\ ${ }^{a}$ Cooperative Institute for Meteorological Satellite Studies, University of Wisconsin-Madison, Madison, Wisconsin \\ ${ }^{\mathrm{b}}$ Atmospheric and Environmental Research, Inc., Lexington, Massachusetts \\ ${ }^{\mathrm{c}}$ School of Meteorology, University of Oklahoma, Norman, Oklahoma \\ ${ }^{\mathrm{d}}$ National Drought Mitigation Center, University of Nebraska-Lincoln, Lincoln, Nebraska \\ ${ }^{\mathrm{e}}$ Hydrology and Remote Sensing Laboratory, Agricultural Research Service, U.S. Department \\ of Agriculture, Beltsville, Maryland \\ ${ }^{\mathrm{f}}$ Earth Science Branch, NASA Marshall Space Flight Center, Huntsville, Alabama
}

(Manuscript received 15 August 2018, in final form 11 January 2019)

\begin{abstract}
This study examines the evolution of soil moisture, evapotranspiration, vegetation, and atmospheric conditions during an unusual flash drought-flash recovery sequence that occurred across the south-central United States during 2015. This event was characterized by a period of rapid drought intensification (flash drought) during late summer that was terminated by heavy rainfall at the end of October that eliminated the extreme drought conditions over a 2-week period (flash recovery). A detailed analysis was performed using time series of environmental variables derived from meteorological, remote sensing, and land surface modeling datasets. Though the analysis revealed a similar progression of cascading effects in each region, characteristics of the flash drought such as its onset time, rate of intensification, and vegetation impacts differed between regions due to variations in the antecedent conditions and the atmospheric anomalies during its growth. Overall, flash drought signals initially appeared in the near-surface soil moisture, followed closely by reductions in evapotranspiration. Total column soil moisture deficits took longer to develop, especially in the western part of the region where heavy rainfall during the spring and early summer led to large moisture surpluses. Large differences were noted in how land surface models in the North American Land Data Assimilation System depicted soil moisture evolution during the flash drought; however, the models were more similar in their assessment of conditions during the flash recovery period. This study illustrates the need to use multiple datasets to track the evolution and impacts of rapidly evolving flash drought and flash recovery events.
\end{abstract}

\section{Introduction}

The 2015 growing season across the south-central United States was characterized by an unusual sequence of events that saw parts of the region flip from extreme drought conditions to a pluvial during the spring, followed by a rapidly intensifying flash drought (Otkin et al. 2018a) during the latter half of summer, and then an abrupt termination of drought conditions near the end of October. At the beginning of April, the U.S. Drought Monitor (USDM; Svoboda et al. 2002) depicted severe-to-exceptional drought within a broad area extending from the Texas panhandle and western

Corresponding author: Jason A. Otkin, jason.otkin@ssec.wisc. edu
Oklahoma southward across most of central Texas. The extreme drought conditions at that time primarily represented the impact of long-term precipitation deficits accumulated during the previous 4 years. The situation, however, rapidly improved during the spring due to an extended period of exceptionally heavy rainfall that completely eradicated drought conditions, as depicted by the USDM, by the end of May. This pluvial was so extensive that statewide precipitation records were set for both Texas and Oklahoma during May (NOAA 2016).

Conditions remained very moist across the southcentral United States during the first part of summer; however, a period of below normal rainfall and elevated evaporative demand commenced in July and persisted in many regions until the middle of October. The rapid 
onset of the unusually hot and dry weather conditions allowed drought to quickly develop across eastern Texas and Louisiana during the latter half of July. Drought conditions then rapidly expanded to cover the entire region from central Texas to Mississippi, with many locations that were drought-free at the end of July being characterized by extreme or even exceptional drought conditions only 2-3 months later according to the USDM. The rapid drought development across central and eastern Texas was especially noteworthy because widespread flooding had occurred across that region only 2 months prior to the onset of drought conditions. This rapid transition to drought is consistent with the flash drought definition presented by Otkin et al. (2018a) that identifies flash droughts based on their unusually rapid intensification. As drought conditions intensified, decreased soil moisture severely impacted agricultural production across the region (USDA 2015a). Wildfire activity was also enhanced (NOAA 2015) because the heavy rainfall during the spring promoted extensive plant growth that then provided abundant fuel sources for fires once conditions became drier (Scasta et al. 2016).

After exhibiting nearly continuous development over a 3-month period, the flash drought abruptly ended during the last week of October due to heavy rainfall across the entire region. The copious precipitation resulted from the interaction between a stalled frontal boundary in the lower troposphere and abundant tropical moisture streaming northward from Hurricane Patricia which, prior to making landfall in southern Mexico, had been the strongest hurricane on record in the western hemisphere (Rogers et al. 2017). Additional heavy rainfall during the following week meant that drought conditions were eradicated from most of the region less than 2 weeks after they had reached extreme to exceptional intensity according to the USDM. This represents the second example of "flash recovery" across this region during 2015 (the previous example occurring in the spring) whereby extreme drought conditions were rapidly eliminated over a short time period due to very heavy precipitation. The "flash recovery" terminology introduced here is complementary to "flash drought" because they both refer to very rapid (but opposite) changes in drought conditions. The rapid oscillations between wet and dry extremes during 2015 were notable both for their large spatial extent and magnitude and for their rapid development over subseasonal time scales. Indeed, a remarkable aspect of 2015, from a climate perspective, is that Texas and Oklahoma each recorded their wettest calendar years on record (NOAA 2015) despite large areas of both states experiencing severe drought conditions on more than one occasion.

In this paper, we will examine the evolution of the soil moisture and vegetation health conditions as the region rapidly transitioned from the springtime pluvial into flash drought during the latter half of the growing season and then emerged free of drought after the flash recovery at the end of October. This will be accomplished using high-resolution estimates of soil moisture and vegetation health obtained using satellite-based retrievals and sophisticated land surface models. The evolution of vegetation indicators depicting evapotranspiration (ET) and leaf area index (LAI) will be compared to soil moisture estimates from the North American Land Data Assimilation System (NLDAS; Xia et al. 2012a,b) and to observed precipitation and near-surface atmospheric conditions. The analysis will examine the congruence between the datasets as drought conditions intensified and then rapidly abated, while also assessing differences in timing as the drought impacts cascaded from one variable to another. The datasets and methodology are described in section 2 . The evolution of the flash drought and flash recovery events is examined in section 3 , with conclusions and a discussion presented in section 4 .

\section{Data and methodology}

\section{a. U.S. Drought Monitor}

A USDM drought analysis is generated each week through expert synthesis of various data sources (Svoboda et al. 2002). Given the wide range of potential drought impacts, numerous drought indicators are used when creating the weekly analyses. These typically include precipitation, soil moisture, surface streamflow, reservoir levels, and snowpack. In recent years, other metrics depicting anomalies in evaporative demand, ET, and vegetation health have also become better integrated into the USDM drought analysis process due to more accurate observations and satellite retrieval algorithms. Qualitative sources such as drought impact and crop condition reports provide additional guidance when delineating areas affected by drought and determining drought severity. The USDM analyses depict abnormally dry conditions (D0), and four drought categories including moderate (D1), severe (D2), extreme (D3), and exceptional (D4) drought.

\section{b. Meteorological variables}

Near surface atmospheric conditions were evaluated using Climate Forecasting System Reanalysis data available every $6 \mathrm{~h}$ on an $\sim 38-\mathrm{km}$ resolution grid 
(Saha et al. 2010). Standardized anomalies were computed for 2-m temperature (T2M), 2-m dewpoint depression (DPD), downwelling shortwave radiation (DSW), and 10-m wind speed (WSPD) averaged over 2- and 4-week periods and updated weekly using data from 1979 to 2017. These variables were chosen because they are important drivers of evaporative demand (Otkin et al. 2013; Hobbins et al. 2016; McEvoy et al. 2016; Hobbins 2016). An alternative would be to assess changes in evaporative demand itself; however, additional insight regarding seasonal and regional differences can be gained by examining these variables individually. Daily gridded precipitation analyses with $0.25^{\circ}$ resolution were also obtained from the Climate Prediction Center precipitation analysis (Higgins et al. 2000) and summed to create 4-, 8-, and 12-week accumulated precipitation. Standardized precipitation index (SPI; McKee et al. 1993) anomalies were then computed at weekly intervals using data from 1948 to 2017. Together, the SPI and near surface atmospheric anomalies provide greater context for the evolution of this event.

\section{c. North American Land Data Assimilation System}

Topsoil (TS; 0-10 cm) and total column (TC; 0-2 m) soil moisture conditions were evaluated using $0.125^{\circ}$ resolution output from the Noah (Ek et al. 2003; Barlage et al. 2010; Wei et al. 2013), Mosaic (Koster and Suarez 1996), and Variable Infiltration Capacity (VIC; Liang et al. 1996) land surface models included in the NLDAS-2 (Xia et al. 2012a,b). Hourly data for each model and the ensemble mean (hereafter referred to as NMV) in the TS and TC layers were averaged over 2- and 4-week time periods, with standardized anomalies computed at weekly intervals using data from 1979 to 2017. Each model uses a set of energy and water balance equations to simulate the evolution of soil moisture and temperature in multiple layers of the soil profile. Though each model uses the same precipitation and atmospheric forcing datasets, their response to this forcing can differ due to the use of different vegetation and soil datasets and different approximations for key processes such as drainage, evaporation, and vegetation rooting depth. The soil moisture response of each land surface model during the flash drought and flash recovery will be compared to the ensemble mean soil moisture anomalies and to the other drought indicators to determine which models most accurately represented the evolution of these events.

\section{d. Soil Moisture Active Passive}

Additional information about near-surface $(0-5 \mathrm{~cm})$ soil moisture content across the study domain is obtained using soil moisture retrievals from the Soil Moisture Active Passive (SMAP) sensor that was launched in early 2015. SMAP was originally designed to measure soil moisture and the freeze/thaw state globally with high spatial resolution $(10 \mathrm{~km})$ using an L-band passive radiometer $(1.4 \mathrm{GHz})$ and an L-band active radar $(1.26 \mathrm{GHz})$; however, the radar stopped transmitting data on 7 July 2015. As such, this study uses the coarser-resolution radiometer-based soil moisture retrieval product that is available globally each day with $0.25^{\circ}$ resolution (Entekhabi et al. 2014). In particular, we use the SMAP level 3 daily soil moisture dataset available from the NASA Distributed Active Archive Center. Several verification studies have shown that the SMAP soil moisture product exceeds its expected accuracy and provides useful near-surface soil moisture estimates for a variety of surface types (Chan et al. 2016; Chen et al. 2017; Colliander et al. 2017; Burgin et al. 2017; Ray et al. 2017). SMAP soil moisture retrievals were averaged over 2-week periods, and then standardized anomalies were computed at weekly intervals using data from 2015 to 2017. Note that the very short period of record for SMAP compared to the other variables used in this study means that the magnitudes of the anomalies are not strictly comparable.

\section{e. Evaporative stress index}

Vegetation moisture stress is assessed using the evaporative stress index (ESI; Anderson et al. 2007a, b) that depicts standardized anomalies in a reference ET fraction. With the ESI, the reference ET is computed using a Penman-Monteith formulation (Allen et al. 1998) whereas the actual ET is estimated using satellite data and the Atmosphere-Land Exchange Inverse (ALEXI; Anderson et al. 1997, 2011) model. ALEXI is a two-source energy balance model that computes the latent, sensible, and ground heat fluxes for vegetated and bare soil components of the land surface using the observed rise in land surface temperature during the morning (Norman et al. 1995). Satellite thermal infrared imagery is used to retrieve the land surface temperatures. Closure of the energy balance equations is achieved using the McNaughton and Spriggs (1986) atmospheric boundary layer growth model. Because satellite-based ET estimates can only be computed for clear pixels, daily clear-sky ET fraction analyses are composited over multiweek time periods to achieve more complete domain coverage. For this study, the ESI was computed using 2-, 4-, and 8-week compositing periods to assess moisture stress over both short and long time scales (Otkin et al. 2013). ALEXI is run daily over the contiguous United States, with the ESI computed at weekly intervals during this study using data from 2001 
to 2017. The high spatial resolution $(4 \mathrm{~km})$ of the ESI makes it very useful for monitoring vegetation stress and estimating crop yields (Otkin et al. 2016; Anderson et al. 2016a,b). Readers are referred to Anderson et al. (2007a,b, 2013) for a more detailed description of the ESI.

\section{f. Vegetation biomass}

The impact of the anomalous weather and soil moisture conditions on vegetation biomass is examined using the LAI product derived from Moderate Resolution Imaging Spectroradiometer (MODIS) observations. In particular, the study uses the MOD15A2H product, which is available as 8-day composites with 500-m spatial resolution. LAI is a dimensionless measure of the green leaf area per unit ground area. The reader is referred to Myneni et al. (2002) for more information about the MODIS LAI product. For this study, standardized LAI anomalies over a 2-week compositing period were computed at weekly intervals using data from 2001 to 2017.

\section{Results}

\section{a. Large-scale drought analysis}

This section examines the overall evolution of conditions across the south-central United States from the onset of the flash drought during midsummer through its rapid termination at the end of October. Figure 1 shows the progression of the USDM, ESI, SPI, NMV_TS, NMV TC, SMAP, and T2M datasets at 4-week intervals from 30 June to 17 November 2015. Note that the SPI anomalies were computed using an 8-week accumulation period, whereas the remaining variables either represent instantaneous conditions (e.g., USDM) or were computed using data averaged over a 4 -week period. A longer 8 -week period was used to compute the SPI because vegetation and deeper soil moisture tend to respond to precipitation departures occurring over longer time periods (Anderson et al. 2011).

On 30 June, near normal conditions prevailed across most of the south-central United States, with abnormally dry conditions confined to a few small areas according to the USDM. The good conditions had developed primarily in response to the exceptionally heavy rainfall that occurred across the region during May and June. This is reflected by the very large positive 8-week SPI anomalies extending from Texas northeastward across southern Oklahoma and western Arkansas, as well as the generally positive SPI across the rest of the region. The abundant precipitation promoted the growth of very healthy vegetation as depicted by the positive ESI anomalies across most of the region. The ESI anomalies were largest over Texas where the T2M was also cooler than normal. The positive NMV_TC soil moisture anomalies indicate that the heavy spring rainfall had fully recharged the subsoil moisture content and terminated the hydrological drought in most locations. Likewise, the NMV_TS and SMAP anomalies were mostly positive; however, they were smaller for these near-surface soil moisture variables than they were for the TC soil moisture.

Drought conditions began to intensify during the next 4 weeks in a large area extending from eastern Texas to Mississippi. By 25 August, some parts of the region had experienced a two-category increase in drought severity during the previous 4 weeks according to the USDM. Temperatures had been close to normal except for along the Gulf Coast; however, there was very little rainfall, which led to large negative SPI anomalies from southern Texas to Mississippi. The area characterized by large negative NMV_TS and SMAP soil moisture anomalies continued to expand and roughly aligned with areas containing large rainfall deficits. Large negative NMV_TC soil moisture anomalies had started to develop across the lower Mississippi River valley, whereas the previously large positive soil moisture anomalies across Texas had started to diminish, but remained above normal in most locations. By this time, substantial vegetation stress had also developed across the core drought region as indicated by the large negative ESI. The westward expansion of moderate and severe drought conditions in the USDM into central Texas was primarily due to the onset of large short-term precipitation deficits; however, the neutral to positive ESI and NMV_TC anomalies suggest that the expansion was too large because vegetation and TC soil moisture impacts were confined to areas farther to the east. However, short-term dryness in the TS was becoming more evident across central and western Texas based on the SMAP and NMV_TS datasets.

The flash drought continued to intensify during the next 4 weeks in a large region extending from central Texas to Mississippi. Several areas that were droughtfree 8 weeks earlier were now classified as having extreme (D3) drought by the USDM on 22 September. For these isolated areas, this represents a four-category increase in drought severity over an 8-week period, which is an exceptionally rapid rate of intensification based on the USDM climatology (see Fig. 3 in Otkin et al. 2014). The rapid agricultural and ecological drought development was driven by very large precipitation deficits (meteorological drought) and above average evaporative demand during the preceding 

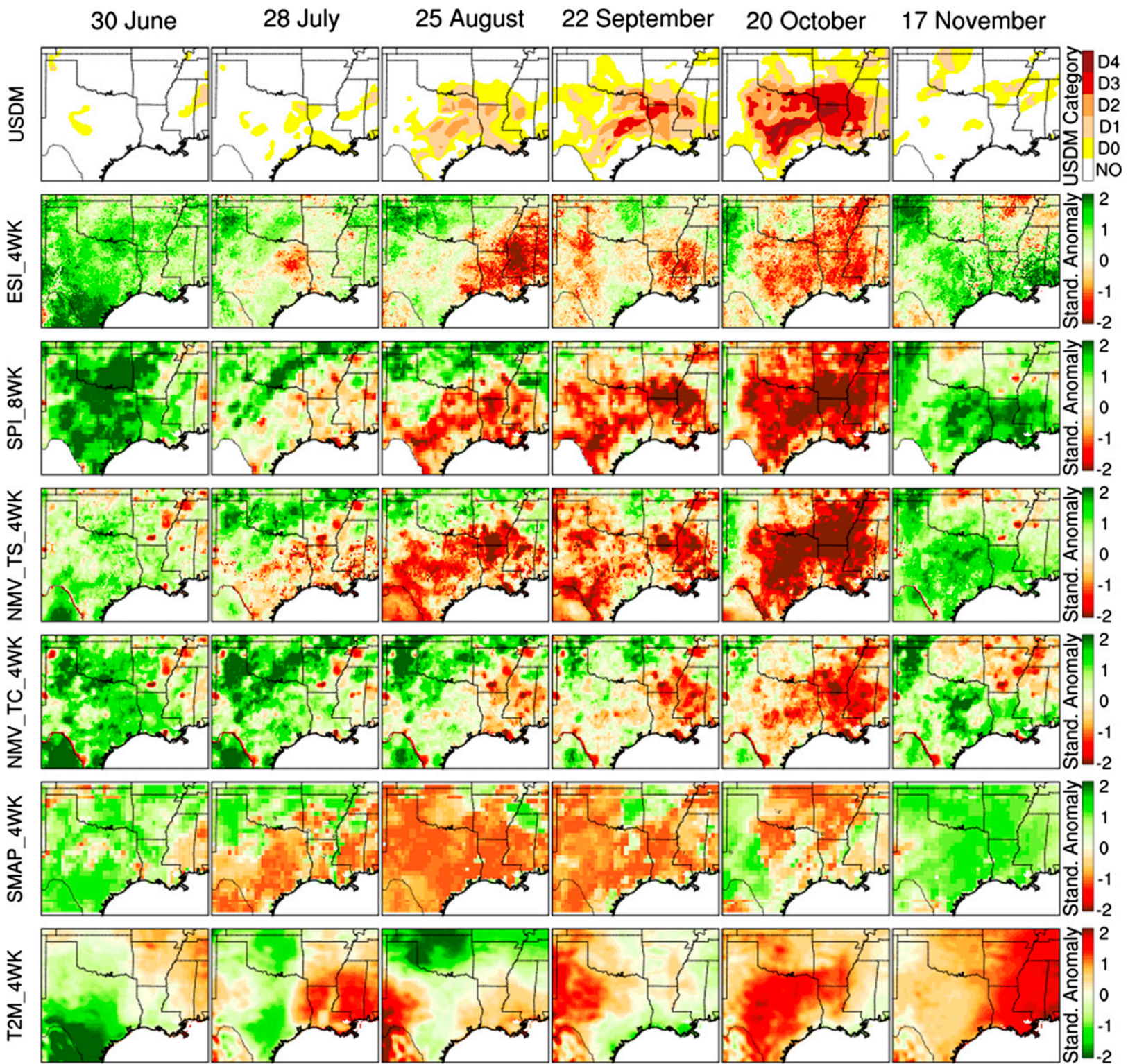

FIG. 1. Evolution of the USDM drought depiction, along with 4-week ESI (ESI_4WK), 8-week SPI (SPI_8WK), modeled 4-week TS and TC soil moisture (NMV_TS_4WK and NMV_TC_4WK, respectively), 4-week SMAP (SMAP_4WK) soil moisture retrievals, and 4-week T2M (T2M_4WK) anomalies shown from 30 Jun to 17 Nov 2015.

2 months. The largest negative ESI anomalies were now confined to Louisiana and Mississippi where the largest NMV_TC soil moisture anomalies were located. Normal to below normal ESI anomalies; however, extended all the way to western Texas where large precipitation and TS moisture deficits had developed. The negative ESI anomalies were especially large in the rolling plains of west Texas where vegetation stress was higher due to large negative SPI anomalies and well above normal temperatures. The SMAP anomalies also depict widespread dryness across the region with the exception of eastern Oklahoma and western Arkansas where more substantial precipitation had recently occurred.

By 20 October, drought conditions had reached their maximum intensity. Severe (D2) to extreme (D3) drought covered an extensive region, including several locations in Texas and Louisiana that were now classified as being in exceptional (D4) drought. The rapid expansion of severe drought across the region was driven by a third consecutive month of well below normal precipitation compounded by the effects of above 
normal temperatures. The longevity and magnitude of the dryness were impressive with places such as Monroe, Louisiana having their driest July-September on record. In addition, a period of extreme heat accompanied by low humidity and strong winds during the middle of October hastened drought development across the region. By 19 October, the U.S. Department of Agriculture reported that the TS moisture was rated as short or very short in more than $80 \%$ of Arkansas, Louisiana, and Mississippi and that crop and pasture conditions had deteriorated greatly across most of the south-central United States (USDA 2015b). Inspection of the ESI, SPI, and NMV_TS anomalies show that very dry conditions had become entrenched across an extensive area. Even the NMV_TC dataset had become strongly negative over a large region centered on Louisiana and Arkansas, indicating that the short-term dryness of previous months had progressed into a longer-term hydrological drought. The geographic scale and intensification rate of the flash drought were very impressive as signified by the extensive region that was free of drought conditions on 28 July that had descended into extreme-to-exceptional drought only 12 weeks later. The unusually rapid intensification sustained over an extended period of time is consistent with the flash drought definition presented in Otkin et al. (2018a).

After experiencing nearly 3 months of unrelenting drought intensification, the flash drought abruptly ended during the last week of October and first week of November when very heavy rainfall fell across most of the region. The precipitation was so heavy that the 8-week SPI anomalies flipped from strongly negative to strongly positive in a broad region extending from Texas to Mississippi over only a 1-2-week period (not shown). A similar transition occurred in all of the variables across this region. Indeed, the sudden transition from negative to positive anomalies during this flash recovery event was stunning in both its geographical extent and magnitude. This was the second instance during 2015 where a large area of extreme drought was rapidly eliminated due to very heavy rainfall. The only exceptions to the much-improved conditions occurred in small areas along the northern periphery of the drought area where recent precipitation totals were insufficient to eliminate the long-term deficits. Even so, the return to mostly neutral to positive anomalies in all datasets except for NMV_TC indicates that conditions had improved across these areas as well. Overall, the story by the middle of November is one of drastic improvement compared to several weeks earlier when flash drought conditions were entrenched across the region.

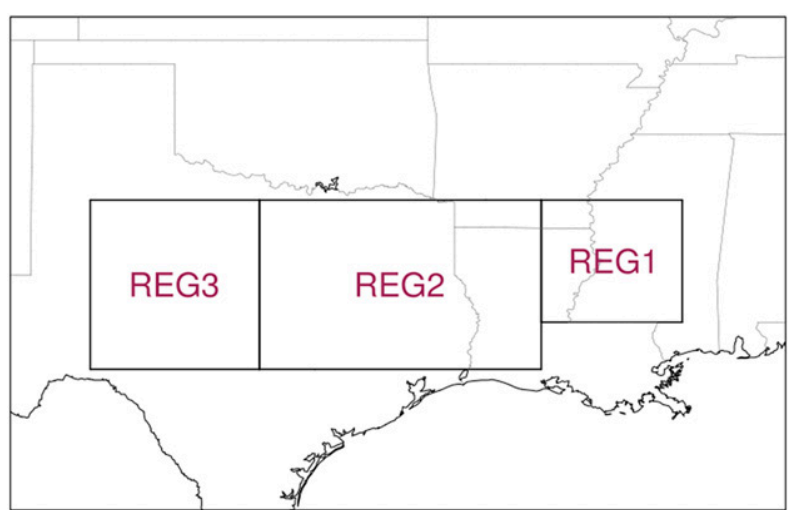

FIG. 2. Map showing the locations of the three regions examined in section 3 .

\section{b. Regional drought analysis}

In this section, we more closely examine the evolution of the flash drought-flash recovery sequence for several locations in the south-central United States that exhibited different drought onset times, drought intensification rates, and maximum severity. These regions are shown in Fig. 2. For each region, the data will be shown at weekly intervals using the visualization tool shown in Fig. 3, which is a concise method to display information from multiple variables and time periods on a single image. Unlike the previous section, the time series show anomalies computed over various time scales and for each individual NLDAS model to provide greater insight into the drought evolution and the ability of the land surface models to simulate soil moisture characteristics during this event. Each data point on a given figure represents the spatial average for a given variable and week for a particular region. The USDM drought analysis is shown in the first column, with 2-week standardized anomalies in T2M, DPD, WSPD, and DSW shown in the next four columns. Note that the color bar is reversed for each of these near-surface atmospheric variables so that positive anomalies indicative of enhanced drying are shown in red and brown colors to be consistent with the other datasets. ESI anomalies computed over 2-, 4-, and 8-week periods are displayed next, followed by SPI anomalies computed over 4- and 12 -week periods, and LAI anomalies computed over a 2-week period. Finally, the last 17 columns show 2-week SMAP anomalies, followed by TS and TC soil moisture anomalies computed over 2- and 4-week periods for the Noah, Mosaic, and VIC models, and for their ensemble mean (NMV).

\section{1) LOWER MISSISSIPPI RIVER VALLEY}

Figure 3 shows the drought evolution for portions of the lower Mississippi River valley including far 


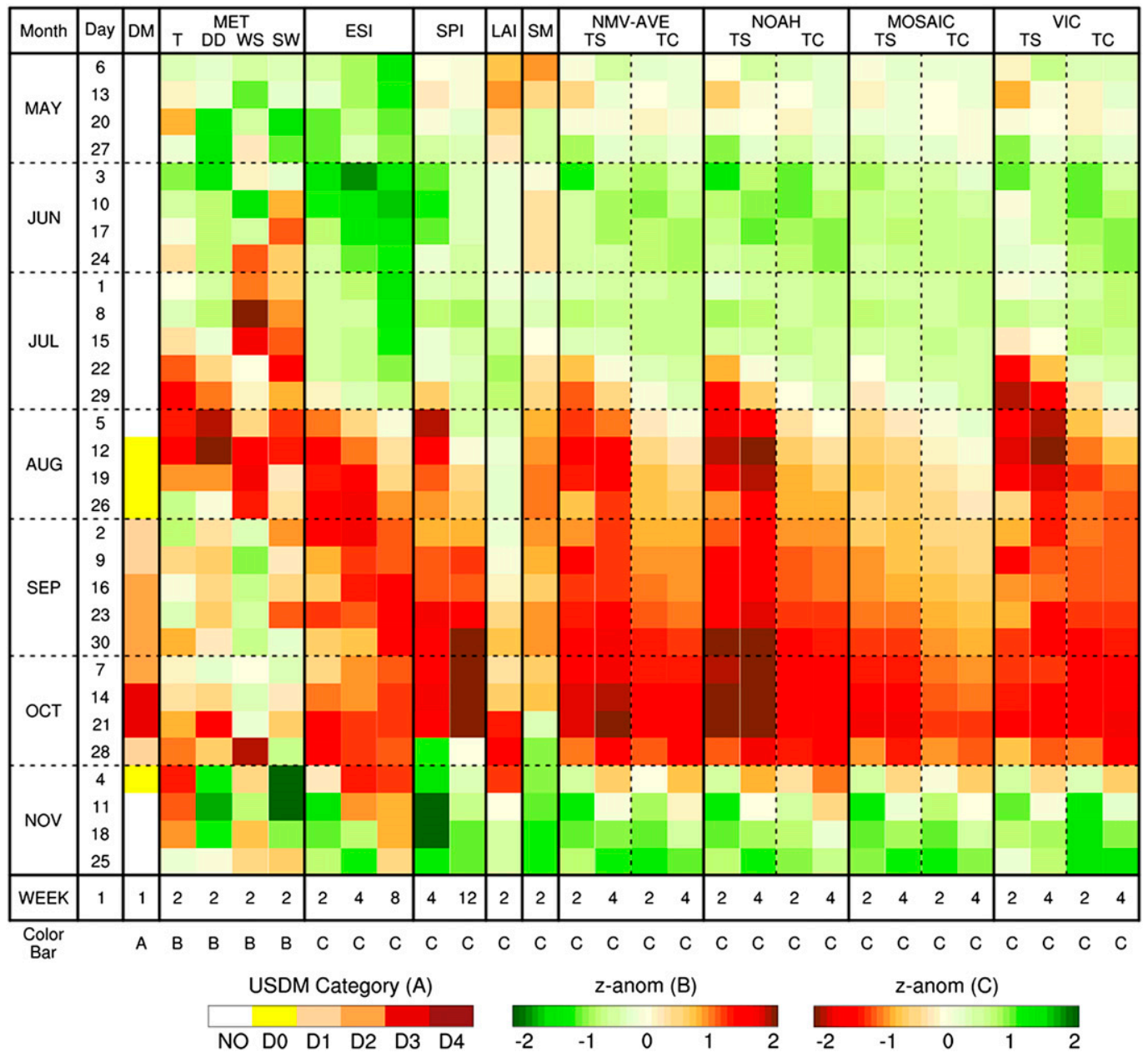

FIG. 3. Drought evolution across Region 1, including northeastern Louisiana, far southeastern Arkansas, and western and central Mississippi, during 2015. The USDM drought analysis is shown in column 1, with 2-week anomalies in T2M, DPD, WSPD, and DSW shown in columns 2-5. ESI anomalies computed over 2-, 4-, and 8-week periods are displayed in columns 6-8, followed by 4- and 12-week SPI anomalies in columns 9-10 and 2-week LAI anomalies in column 11. Column 12 shows the 2-week SMAP soil moisture anomalies, followed by the topsoil and total column soil moisture anomalies for 2- and 4-week periods for the NMV ensemble average and for the Noah, Mosaic, and VIC models, respectively, in columns 13-28. The color bar used to plot a given dataset is shown below each column. Each data point represents the spatial average for a given variable and week across this region.

southeastern Arkansas, northeastern Louisiana, and a large portion of western and central Mississippi, denoted as Region 1 in Fig. 2. At the beginning of May, conditions were generally near normal except for larger negative anomalies in the LAI and SMAP datasets. Most of the datasets indicate that the soil moisture and vegetation conditions began to improve during the latter half of May in response to the onset of above normal precipitation and the continuation of good growing conditions. The positive ESI during June indicates that the vegetation was responding favorably to the abundant soil moisture. The negative anomalies in the SMAP data during June are an outlier and likely represent limitations due to its small period of record.
By the middle of July, however, conditions began to rapidly deteriorate due to the onset of very hot, windy, and sunny weather. The elevated evaporative demand combined with below normal rainfall led to a rapid reversal from positive to negative TS moisture anomalies during the fourth week of July, followed 1 week later by rapid decreases in the 2-week ESI. The reversal in TS moisture preceded the initial appearance of negative 4-week SPI anomalies by 1 week due to the influence of the very high evaporative demand on the TS moisture. The TC soil moisture content also exhibited a rapid decrease near the beginning of August, but with slower response than the TS moisture given the deeper soil column represented in this variable. Even so, 
standardized change anomalies (not shown) indicate that the changes in TC soil moisture were much larger than usual. Large decreases, such as these, over short time periods have been shown to be an indicator of flash drought (Otkin et al. 2014, 2015). It is interesting to note that though all of the NLDAS models had similar soil moisture anomalies at the start of the rapid drying period, the VIC and Noah models depicted much more rapid drying than Mosaic and also exhibited much larger negative anomalies. Overall, the larger soil moisture anomalies in the Noah and VIC models are more consistent with the large atmospheric and 4-week SPI anomalies, all of which would be expected to lead to a rapid drawdown in soil moisture.

The high temperatures starting near the middle of July impacted the vegetation as evidenced by a rapid transition to negative ESI values over a 4-week period. In contrast, anomalies in remotely sensed LAI remained positive until the beginning of September, likely due to the lasting impact of the extensive vegetation growth during the first half of summer. Throughout the summer, however, the LAI anomalies were slowly decreasing due to the prolonged vegetation stress and its impact on biomass production. Compared to near-surface soil moisture datasets, the slower response of the ESI shows that the vegetation was accessing subsoil moisture that was still plentiful during the initial stages of the drought. Indeed, the 8-week ESI closely tracks the evolution of the TC soil moisture whereas the 2-week ESI, which responds more quickly to changing conditions, is a merger of the TS and TC soil moisture signals. Regardless, the rapid decreases in most variables indicate that a flash drought had started to develop by the end of July. The USDM introduced abnormally dry conditions (D0) by the second week of August and then maintained those conditions until the end of August. This depiction may have been too favorable based on the various shortterm indicators examined here that showed much more severe moisture stress.

After some minor improvements during the latter part of August and beginning of September, extremely dry weather returned to the region, which culminated in 12 -week SPI anomalies $<-2.0$ by the end of September that persisted for the next 4 weeks. This was a period of rapid drought intensification according to the USDM, with the drought designation increasing by three categories over a 7-week period. This degradation largely tracked a concomitant decrease in the TC soil moisture and long-term SPI anomalies. Looking back over the previous 3 months, it was the intense heat and very dry conditions over the 5-week period from mid-July to midAugust that initiated the flash drought event, and it was the continuation of elevated evaporative demand and below normal rainfall that promoted its further development over the next 2 months. The persistently negative DPD anomalies throughout this time period, including spikes in the DPD at the beginning of August and the middle of October when temperature extremes were especially large, illustrates that drought was having a large impact on surface moisture availability. Several recent studies by McEvoy et al. (2016), Ford and Labosier (2017), and Otkin et al. (2018b) have shown that larger than normal vapor pressure deficits often occur during flash drought events.

The drought conditions were finally broken at the end of October due to the return of much above normal precipitation as signified by the rapid reversal from large negative to positive SPI anomalies. According to the USDM, the extreme drought conditions were eliminated in only 2 weeks, with abnormal dryness removed during the following week. Given its sensitivity to the top few centimeters of the soil profile, the SMAP data were the first soil moisture dataset to indicate improving conditions, followed closely by the modeled soil moisture content in the TS and then the TC. It is interesting to note that the responses of all of the NLDAS models during the flash recovery period were very similar for both TS and TC despite having very different depictions during the preceding flash drought. Further work will be necessary to identify reasons for these differences because they are very important from a drought monitoring perspective. Finally, the vegetation datasets (ESI and LAI) showed improvement by the second week of November as the plants were able to slowly recover from the drought conditions of the preceding months. This delayed response of the vegetation to improving weather and soil moisture conditions at the end of the flash drought was also noted during the 2012 flash drought across the central United States (Otkin et al. 2016).

\section{2) EASTERN TEXAS AND WESTERN LOUISIANA}

In this section, the drought evolution across eastern Texas, western Louisiana, and extreme southwestern Arkansas (Region 2 in Fig. 2) is examined (Fig. 4). Overall, this region experienced a similar drought evolution to those areas further to the east; however, important differences exist. For example, this region received much heavier precipitation during the spring and early summer that led to very large $(>1.5) 12$-week SPI anomalies. Temperatures were also cooler than normal through the middle of July with the large positive DPD anomalies indicating that conditions were very moist for that time of the year. The ESI and LAI both indicate that the vegetation was very healthy due to the abundant soil moisture and favorable growing conditions. The SMAP and VIC TS moisture datasets 


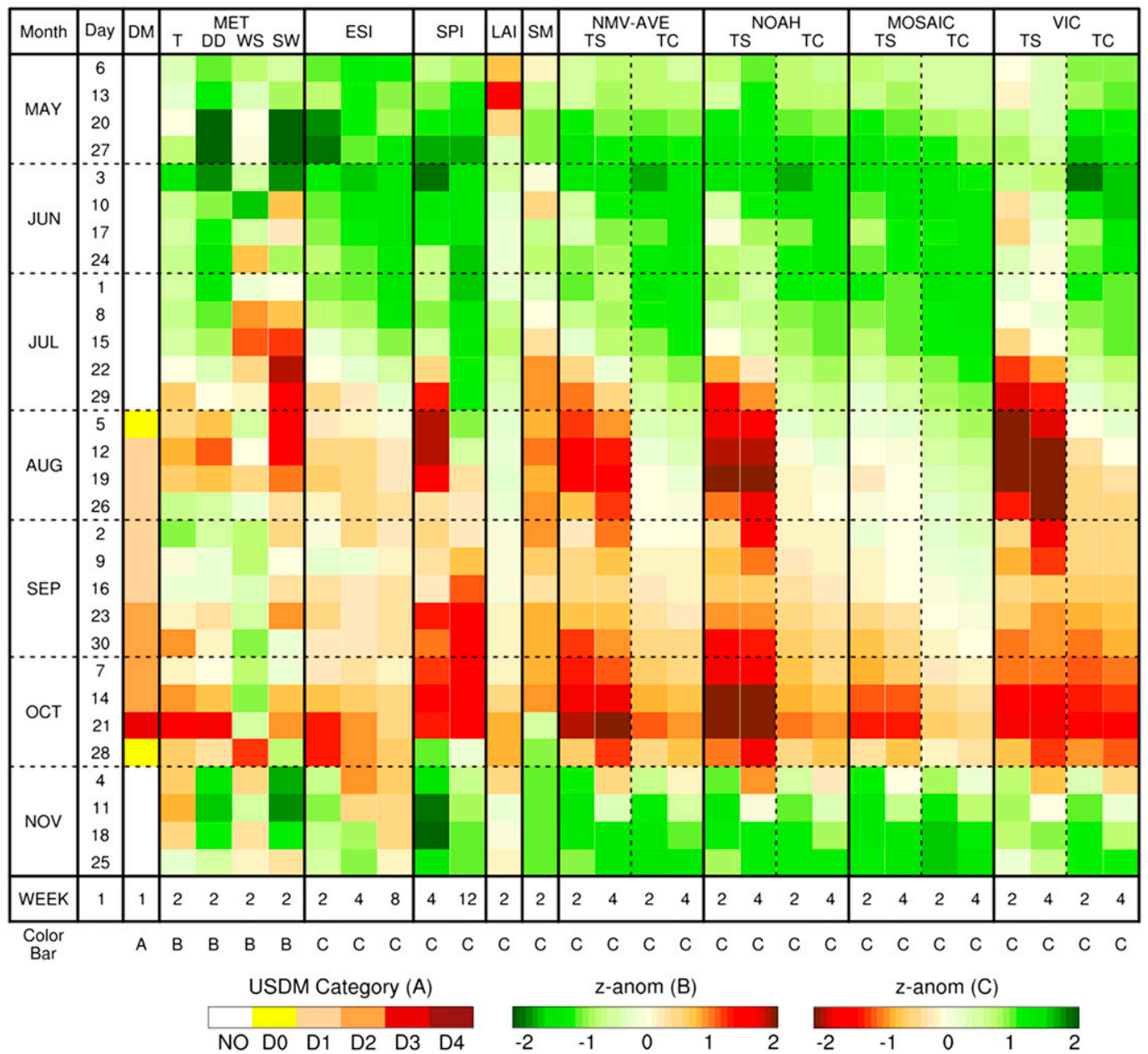

FIG. 4. As in Fig. 3, but showing the drought evolution for Region 2, including eastern Texas, western Louisiana, and extreme southeastern Arkansas.

depict some very minor dryness during mid-June, but overall conditions were very good across the region.

Despite the great start to the growing season, conditions began to rapidly worsen during the second half of July, with the USDM depicting a two-category increase in drought severity during the first 2 weeks of August. The rapid drought onset was driven by an almost complete lack of rainfall during the previous month as evidenced by the very large $(<-2)$ negative 4 -week SPI anomalies, compounded by elevated evaporative demand due to above normal temperatures, sunny skies, and large DPD. The rapid increase in drought severity depicted by the USDM may have been premature because the vegetation and TC soil moisture variables indicate that conditions were at worst only slightly below normal; however, it should be noted that the USDM used the "short-term" drought designation for this area at this time. This is especially pertinent given that the atmospheric and TC soil moisture anomalies were much less severe or even positive across this region compared to areas further to the east where the USDM was slower to depict drought intensification. The main factor that promoted the more severe drought designation in this region by the USDM was the larger short-term rainfall deficits.

Further drought intensification was delayed for several weeks due to occasional minor rainfall events and cooler temperatures from the end of August through the middle of September. Though the sporadic rainfall resulted in some modest improvements to the TS moisture content, the TC soil moisture anomalies became progressively larger during this time period. Because of the increasing subsoil moisture deficits, the vegetation health deteriorated rapidly near the end of September when hotter and drier conditions returned to the area. The ESI and LAI had their largest negative anomalies of the season during September, which indicates that the vegetation response was less robust 
during the second round of extreme heat and dry weather (compared to August) because there was less subsoil moisture for it to access. The development of negative anomalies in both short-term and long-term anomalies in all datasets by the beginning of October represents the transition from short-term dryness to long-term drought conditions in the USDM.

As drought intensified during the second half of the growing season, its depiction both in timing and intensity varied greatly in the NLDAS models. For example, similar to areas further to the east, soil moisture deficits developed much more slowly in the Mosaic model, with the TS and TC soil moisture anomalies remaining neutral to positive until the first part of September. This progression stands in sharp contrast to the Noah and VIC models, both of which depicted very large $(<-2)$ anomalies in TS moisture by the end of July that lasted through most of August. The TC soil moisture also transitioned from positive to negative anomalies by the second week of August in the VIC model followed 1-2 weeks later by the Noah model. It was not until the second round of drought intensification in October that the characteristics of all of the models became similar. Even then, however, the Mosaic model still generated smaller standardized TC soil moisture anomalies than the other models. The large negative 4-week SPI anomalies during the first dry spell followed by the small improvements during late summer and then the development of large negative anomalies in both the short- and long-term SPI during October indicate that the Mosaic model did not realistically represent soil moisture conditions during this drought event.

After a second round of drought development during September and the first part of October, conditions rapidly improved at the end of the month in response to a period of very heavy rainfall, with 2 -week precipitation totals in excess of $25 \mathrm{~cm}$ across much of the region. This rapid reversal is clearly depicted by the 4-week SPI transitioning from strongly negative to strongly positive during the last week of October. Even the longer-term 12-week SPI transitioned from a large negative anomaly $(<-1.5)$ to slightly positive in 1 week. Accordingly, the USDM drought classification improved by four categories in only 2 weeks during this flash recovery event, with the region becoming completely free of drought and abnormally dry conditions by the first week of November. The heavy rainfall also led to the rapid return of positive soil moisture anomalies and subsequently to neutral to slightly positive ESI and LAI anomalies. As occurred in Region 1, the vegetation response to the greatly improved soil moisture conditions was modest, likely due to the lateness of the growing season. The NLDAS models differed somewhat in their depiction of the recovery, with the Mosaic model indicating abundant soil moisture whereas the improvements were smallest in the VIC model.

\section{3) Central and western Texas}

Figure 5 shows the drought evolution across central and western Texas extending from the Great Plains in the west to the Hill Country in the east (Region 3 in Fig. 2). Unlike Regions 1 and 2, this region contained moderate drought (D1) conditions at the beginning of May. This designation in the USDM reflected the lingering impacts of long-term hydrological drought because all of the vegetation and soil moisture datasets showed good conditions at this time. A period of above normal precipitation that commenced in April led to the removal of drought in the USDM by the end of May and the onset of large positive anomalies that persisted in most datasets until the middle of July. A notable exception to these above normal conditions is the TS moisture anomalies from the VIC model, which became negative during the second week of June and then remained that way for most of the summer. Despite having slightly below normal TS moisture anomalies, VIC actually had the largest positive $(>1.5)$ TC soil moisture anomalies of the three models. Though there is some support for the slightly negative TS moisture anomalies based on the SMAP soil moisture retrievals, they appear inconsistent with the large SPI anomalies and cooler than normal temperatures across the region.

Conditions started to deteriorate during the second half of July due to the arrival of hotter, windier, sunnier, and drier than normal weather that persisted almost until the end of August. These conditions led to a steady decrease in TS moisture according to SMAP and each of the NLDAS land surface models. Though TS moisture was decreasing, the ESI suggests that the abundant subsoil moisture allowed the vegetation to transpire at a normal to slightly above normal rate for that time of the year. The positive LAI anomalies also slowly decayed during this time period and became slightly negative by the beginning of September. Together, these results indicate that although the vegetation and TC soil moisture were still near normal due to the heavy rainfall from earlier in the growing season, conditions were at a tipping point and could rapidly deteriorate if less favorable conditions developed. Above-normal temperatures unfortunately returned to the region near the beginning of September, which combined with a continuation of much below normal precipitation, led to a steady decrease in the ESI and LAI anomalies. Each of these datasets reached their largest negative values during October. The USDM introduced moderate 


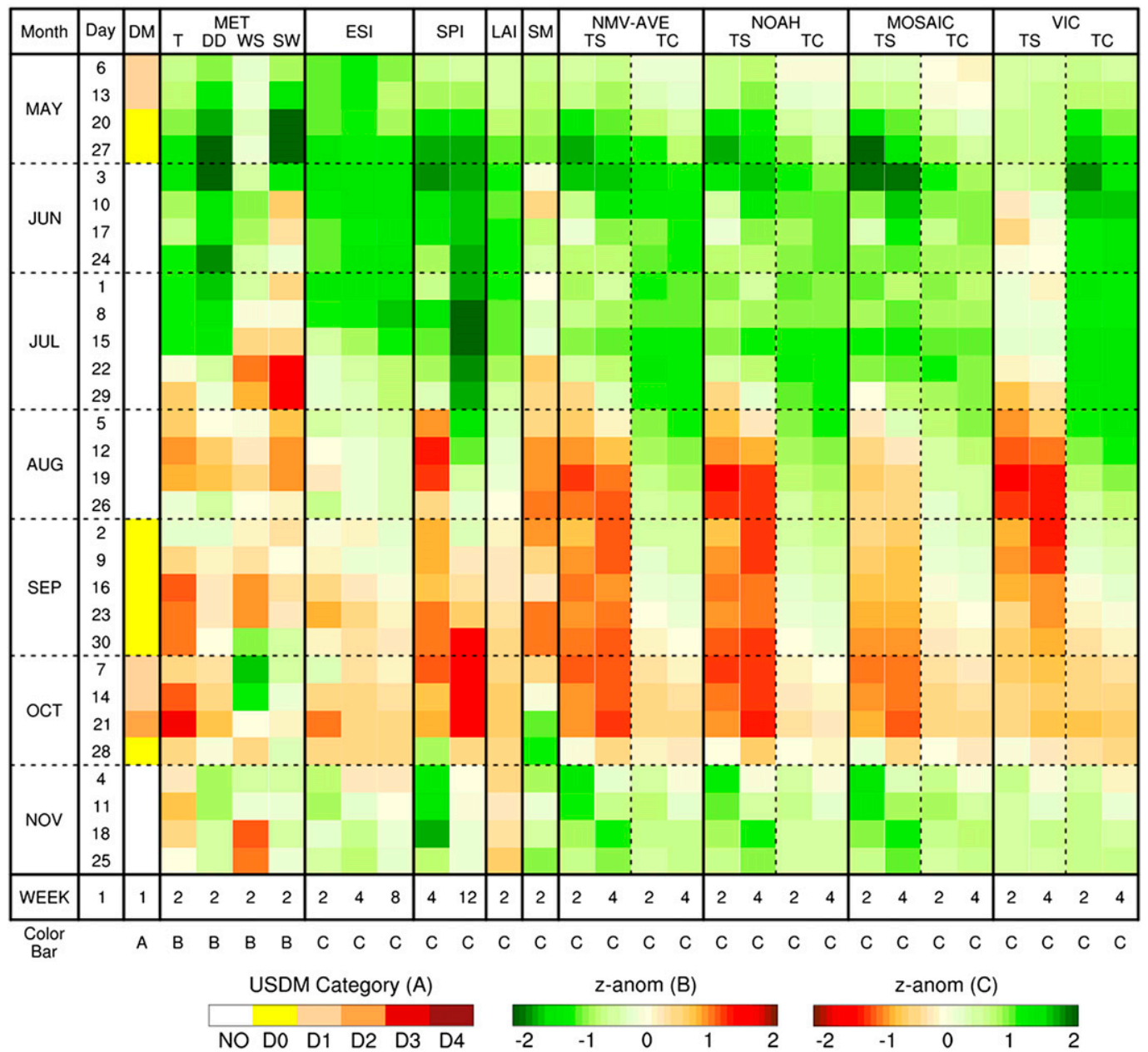

FIG. 5. As in Fig. 3, but showing the drought evolution for Region 3, including western and central Texas.

drought (D1) during the first week of October, with severe drought (D2) depicted 3 weeks later. The increasingly negative 12-week SPI anomalies as the fall progressed indicated that long-term drought was once again encroaching upon the region. Though the drought was not as severe as in the other two regions, this reversal was impressive considering the record rainfall and excellent growing conditions that prevailed earlier in the year.

Similar to Regions 1 and 2, heavy precipitation occurred during the last week of October with above normal precipitation continuing through most of November. The precipitation surplus during this time period was not as large here as it was in the eastern regions; however, the initial drought conditions were also less severe. The end result was the same because the USDM depicted a three-category improvement in only 2 weeks. The heavy rainfall during this flash recovery period led to positive SMAP and modeled soil moisture anomalies extending through the depth of the soil profile. The vegetation also responded favorably to the wetter conditions as indicated by the slightly positive ESI. The LAI also showed some modest improvements, but it was too late in the growing season for substantial vegetation growth to occur.

\section{Conclusions and discussion}

This study documented the evolution of soil moisture and vegetation conditions during a flash drought-flash recovery sequence that occurred across the southcentral United States in 2015. Flash recovery in this context refers to a short period of rapidly improving conditions, whereas flash drought refers to a multiweek period of rapid deterioration. The evolution of two satellite-derived vegetation health metrics, including the ESI and LAI, were compared to SMAP near-surface soil moisture retrievals and to TS and TC soil moisture estimates from three NLDAS models. Soil moisture anomalies were assessed separately for the Noah, 
Mosaic, and VIC models to provide more detailed insight into their performance during these extreme events. The general progression of these datasets was compared to the observed near-surface atmospheric conditions over the south-central United States and for three smaller regions within it.

Overall, a broadly similar evolution of the soil moisture and vegetation conditions occurred across each region. For example, the rapid onset of below normal precipitation and above normal evaporative demand during the middle of summer was accompanied by decreases in near-surface (SMAP) and TS (NLDAS) moisture and increases in vegetation stress signified by the transition to a negative ESI. As the flash drought event continued to intensify, these initial impacts cascaded into below normal vegetation biomass and TC soil moisture according to the LAI and NLDAS datasets. The drought conditions reached their maximum intensity by the middle of October and were then rapidly eliminated at the end of the month. This sequence of events was driven primarily by exceptionally heavy precipitation during the spring and early summer, followed by several months of much drier and hotter weather conditions that promoted flash drought development, and then the return of widespread heavy rainfall during the last week of October and first half of November that led to flash recovery.

Though the analysis revealed a broadly similar progression of cascading effects in each region, specific characteristics of the flash drought such as its onset time and rate of intensification differed across the regions. Flash drought developed earliest in the central and eastern regions where the late summer rainfall deficits and evaporative demand were largest. Despite having similar onset times, the flash droughts evolved differently across these two regions because of differences in the antecedent conditions and the magnitude of the meteorological anomalies. In the eastern region, the early summer rainfall was not as extensive as it was in the central region, which meant that conditions deteriorated more quickly once the weather became hotter and drier at the end of July. This was reflected by the steady decrease in the LAI, 8-week ESI, and NLDAS TC soil moisture anomalies during the second half of the growing season. Only the TS moisture and shorterduration ESI anomalies showed minor improvements during this period when the meteorological anomalies were less extreme.

In contrast, the central region had much larger positive precipitation and TC soil moisture anomalies before the onset of the flash drought that made it more resilient to drought. A 4-week break in the extreme weather conditions starting at the end of August resulted in a temporary cessation of drought development until drier and hotter weather returned by the middle of September. This break, however, did not extend to the TC soil moisture, which steadily decreased during the second half of the growing season. This was a more complicated evolution than occurred in the eastern region and could be viewed either as two distinct periods of flash drought development lasting for 1 month each or as a single flash drought that had a short period of slower drought intensification embedded within it. From a drought early warning and monitoring perspective, the results demonstrate the importance of using multiple datasets to capture the cascading impacts of decreasing soil moisture and deteriorating vegetation conditions due to a sustained period of below normal rainfall and enhanced evaporative demand. This sequence is consistent with a study by Otkin et al. (2018c) that documented the evolution of a flash drought event across the northern High Plains using various drought monitoring datasets and postevent survey responses from agricultural stakeholders.

Comparison of the soil moisture anomalies revealed large differences in how each NLDAS model depicted the evolution of the flash drought event. The largest TS moisture anomalies occurred with the Noah and VIC models and were most noticeable during the onset of the flash drought across the central and eastern regions. In contrast, the Mosaic model generally depicted the wettest conditions in both the TS and TC datasets. This was especially true in the central region where the TS and TC anomalies remained neutral to slightly positive until the first half of September whereas the other two models depicted much drier conditions, especially in the TS. Differences such as this are important from a drought monitoring perspective because they impact the estimated drought severity and which regions are denoted as being in drought. This points toward the need to perform more process-based studies to understand the underlying reasons for these differences. In general, the ensemble average of the land surface models (NMV_AVE) contained a more accurate representation of the flash drought evolution than the individual models. This is consistent with the drought monitoring approach advocated by Xia et al. (2014). Future work includes conducting additional studies to assess the accuracy of land surface models during other flash drought events and in identifying ways to improve their performance.

Finally, to our knowledge, this is the first time that the term "flash recovery" has been used to describe events where extreme drought conditions were rapidly eliminated by exceptionally heavy precipitation over a short period of time. With the recent interest in 
understanding the causes and characteristics of flash drought events characterized by unusually rapid intensification rates, it is prudent to also explore situations where drought conditions are rapidly ameliorated. Better forecasts of flash recovery events are perhaps equally important to improved drought intensification forecasts because they also have a large impact on the health and productivity of native vegetation and crops. Results from this study and from Otkin et al. (2016) have indicated that the vegetation response can be delayed by several weeks after the meteorological conditions improve because the plants either went into dormancy during the drought or were too badly damaged to fully recover over a short period of time. This illustrates that flash recovery from a meteorological or hydrological perspective may not translate into improved forage and grain yields. Future studies are necessary to better characterize flash recovery events and to understand their impacts on vulnerable stakeholders.

Acknowledgments. This work was supported by funds provided by the NASA Soil Moisture Active Passive (SMAP) program under Grant NNH16CT05C. The authors also thank three anonymous reviewers for providing comments that improved the manuscript.

\section{REFERENCES}

Allen, R. G., L. S. Pereira, D. Raes, and M. Smith, 1998: Crop evapotranspiration: Guidelines for computing crop water requirements. FAO Irrigation and Drainage Paper 56, 300 pp., www.fao.org/docrep/X0490E/X0490E00.htm.

Anderson, M. C., J. M. Norman, G. R. Diak, W. P. Kustas, and J. R. Mecikalski, 1997: A two-source time-integrated model for estimating surface fluxes using thermal infrared remote sensing. Remote Sens. Environ., 60, 195-216, https://doi.org/ 10.1016/S0034-4257(96)00215-5.

,$\frac{1}{-}$ J. R. Mecikalski, J. A. Otkin, and W. P. Kustas, 2007a: A climatological study of evapotranspiration and moisture stress across the continental United States based on thermal remote sensing: 1. Model formulation. J. Geophys. Res., 112, D10117, https://doi.org/10.1029/2006JD007506.

,,,,---- and $-2007 \mathrm{~b}$ : A climatological study of evapotranspiration and moisture stress across the continental United States based on thermal remote sensing: 2. Surface moisture climatology. J. Geophys. Res., 112, D11112, https:// doi.org/10.1029/2006JD007507.

- C. Hain, B. Wardlow, A. Pimstein, J. R. Mecikalski, and W. P. Kustas, 2011: Evaluation of drought indices based on thermal remote sensing and evapotranspiration over the continental United States. J. Climate, 24, 2025-2044, https://doi.org/ 10.1175/2010JCLI3812.1.

,-- J. J. Otkin, X. Zhan, K. Mo, M. Svoboda, B. Wardlow, and A. Pimstein, 2013: An intercomparison of drought indicators based on thermal remote sensing and NLDAS simulations. J. Hydrometeor., 14, 1035-1056, https://doi.org/10.1175/ JHM-D-12-0140.1.
— , and Coauthors, 2016a: An energy balance approach for mapping crop water stress and yield impacts over the Czech Republic. Climate Res., 70, 215-230, https://doi.org/10.3354/ cr01411.

, C. Zolin, P. Sentelhas, C. R. Hain, K. Semmens, M. T. Yilmaz, F. Gao, J. A. Otkin, and R. Tetrault, 2016b: Assessing correlations of satellite-derived evapotranspiration, precipitation, and leaf area index anomalies with yields of major Brazilian crops. Remote Sens. Environ., 174, 82-99, https:// doi.org/10.1016/j.rse.2015.11.034.

Barlage, M., and Coauthors, 2010: Noah land surface model modifications to improve snowpack prediction in the Colorado Rocky Mountains. J. Geophys. Res., 115, D22101, https:// doi.org/10.1029/2009JD013470.

Burgin, M. S., and Coauthors, 2017: A comparative study of the SMAP passive soil moisture product with existing satellite-based soil moisture products. IEEE Trans. Geosci. Remote Sens., 55, 2959-2971, https://doi.org/10.1109/ TGRS.2017.2656859.

Chan, S. K., and Coauthors, 2016: Assessment of SMAP passive soil moisture product. IEEE Trans. Geosci. Remote Sens., 54, 4994-5007, https://doi.org/10.1109/TGRS.2016.2561938.

Chen, F., and Coauthors, 2017: Application of triple collocation in ground-based validation of Soil Moisture Active/Passive (SMAP) level 2 data products. IEEE J. Sel. Top. Appl. Earth Obs. Remote Sens., 10, 489-502, https://doi.org/10.1109/ JSTARS.2016.2569998.

Colliander, A., and Coauthors, 2017: Validation of SMAP surface soil moisture products with core validation sites. Remote Sens. Environ., 191, 215-231, https://doi.org/10.1016/ j.rse.2017.01.021.

Ek, M. B., K. E. Mitchell, Y. Lin, E. Rogers, P. Grunmann, V. Koren, G. Gayno, and J. D. Tarpley, 2003: Implementation of Noah land surface model advances in the National Centers for Environmental Prediction operational mesoscale Eta model. J. Geophys. Res., 108, 8851, https://doi.org/10.1029/ 2002JD003296.

Entekhabi, D., and Coauthors, 2014: SMAP Handbook Soil Moisture Active Passive: Mapping Soil Moisture and Freeze/ Thaw from Space. JPL CL14-2285, Jet Propulsion Laboratory, 180 pp., https://smap.jpl.nasa.gov/files/smap2/SMAP Handbook_FINAL_1_JULY_2014_Web.pdf.

Ford, T. W., and C. F. Labosier, 2017: Meteorological conditions associated with the onset of flash drought in the eastern United States. Agric. For. Meteor., 247, 414-423, https://doi.org/ 10.1016/j.agrformet.2017.08.031.

Higgins, R. W., W. Shi, E. Yarosh, and R. Joyce, 2000: Improved United States precipitation quality control system and analysis. NCEP/Climate Prediction Center Atlas 7, NOAA, 40 pp., http://www.cpc.ncep.noaa.gov/research_papers/ncep_cpc_atlas/ 7/toc.html.

Hobbins, M. T., 2016: The variability of ASCE standardized reference evapotranspiration: A rigorous, conus-wide decomposition and attribution. Trans. ASABE, 59, 561-576, https:// doi.org/10.13031/trans.59.10975.

, A. Wood, D. J. McEvoy, J. L. Huntington, C. Morton, and J. Verdin, 2016: The Evaporative Demand Drought Index. Part I: Linking drought evolution to variations in evaporative demand. J. Hydrometeor., 17, 1745-1761, https://doi.org/10.1175/ JHM-D-15-0121.1.

Koster, R. D., and M. J. Suarez, 1996: Energy and water balance calculations in the Mosaic LSM. NASA Tech. Memo. 104606, Vol. 9, 60 pp., http://gmao.gsfc.nasa.gov/pubs/docs/Koster130.pdf. 
Liang, X., E. F. Wood, and D. P. Lettenmaier, 1996: Surface and soil moisture parameterization of the VIC-2L model: Evaluation and modifications. Global Planet. Change, 13, 195-206, https://doi.org/10.1016/0921-8181(95)00046-1.

McEvoy, D. J., J. L. Huntington, M. T. Hobbins, A. Wood, C. Morton, M. Anderson, and C. Hain, 2016: The Evaporative Demand Drought Index. Part II: CONUS-wide assessment against common drought indicators. J. Hydrometeor., 17, 1763-1779, https://doi.org/10.1175/JHM-D-15-0122.1.

McKee, T. B., N. J. Doesken, and J. Kleist, 1993: The relationship of drought frequency and duration to time scale. Preprints, Eighth Conf. on Applied Climatology, Anaheim, CA, Amer. Meteor. Soc., 179-184.

McNaughton, K. G., and T. W. Spriggs, 1986: A mixed-layer model for regional evaporation. Bound.-Layer Meteor., 34, 243-262, https://doi.org/10.1007/BF00122381.

Myneni, R. B., and Coauthors, 2002: Global products of vegetation leaf area and fraction absorbed by PAR from year of MODIS data. Remote Sens. Environ., 83, 214-231, https://doi.org/ 10.1016/S0034-4257(02)00074-3.

NOAA, 2015: September 2015 drought report. Accessed 7 July 2018, https://www.ncdc.noaa.gov/sotc/drought/201509.

—_, 2016: National Climate Report-Annual 2015. Accessed 7 July 2018, https://www.ncdc.noaa.gov/sotc/national/201513.

Norman, J. M., W. P. Kustas, and K. S. Humes, 1995: A two-source approach for estimating soil and vegetation energy fluxes from observations of directional radiometric surface temperature. Agric. For. Meteor., 77, 263-292, https://doi.org/10.1016/ 0168-1923(95)02265-Y.

Otkin, J. A., M. C. Anderson, C. Hain, I. Mladenova, J. Basara, and M. Svoboda, 2013: Examining flash drought development using the thermal infrared based Evaporative Stress Index. J. Hydrometeor., 14, 1057-1074, https://doi.org/10.1175/ JHM-D-12-0144.1.

,,,--- and M. Svoboda, 2014: Examining the relationship between drought development and rapid changes in the Evaporative Stress Index. J. Hydrometeor., 15, 938-956, https://doi.org/10.1175/JHM-D-13-0110.1.

,,-- and $\longrightarrow, 2015$ : Using temporal changes in drought indices to generate probabilistic drought intensification forecasts. J. Hydrometeor., 16, 88-105, https://doi.org/ 10.1175/JHM-D-14-0064.1.

, and Coauthors, 2016: Assessing the evolution of soil moisture and vegetation conditions during the 2012 United States flash drought. Agric. For. Meteor., 218-219, 230-242, https:// doi.org/10.1016/j.agrformet.2015.12.065.

, M. Svoboda, E. D. Hunt, T. W. Ford, M. C. Anderson, C. Hain, and J. B. Basara, 2018a: Flash droughts: A review and assessment of the challenges imposed by rapid onset droughts in the United States. Bull. Amer. Meteor. Soc., 99, 911-919, https://doi.org/10.1175/BAMS-D-17-0149.1.
—, Y. Zhong, D. Lorenz, M. C. Anderson, and C. Hain, 2018b: Exploring seasonal and regional relationships between the Evaporative Stress Index and surface weather and soil moisture anomalies across the United States. Hydrol. Earth Syst. Sci., 22, 5373-5386, https://doi.org/10.5194/hess-22-5373-2018.

—, T. Haigh, A. Mucia, M. C. Anderson, and C. R. Hain, 2018c: Comparison of agricultural stakeholder survey results and drought monitoring datasets during the 2016 U.S. Northern Plains flash drought. Wea. Climate Soc., 10, 867-883, https:// doi.org/10.1175/WCAS-D-18-0051.1.

Ray, R. L., A. Fares, Y. He, and M. Temimi, 2017: Evaluation and inter-comparison of satellite soil moisture products using in situ observations over Texas, U.S. Water, 9, 372, https:// doi.org/10.3390/w9060372.

Rogers, R. F., and Coauthors, 2017: Rewriting the tropical record books: The Extraordinary intensification of Hurricane Patricia (2015). Bull. Amer. Meteor. Soc., 98, 2091-2112, https:// doi.org/10.1175/BAMS-D-16-0039.1.

Saha, S., and Coauthors, 2010: The NCEP Climate System Forecast Reanalysis. Bull. Amer. Meteor. Soc., 91, 1015-1057, https:// doi.org/10.1175/2010BAMS3001.1.

Scasta, J. D., J. R. Wein, and M. C. Stambaugh, 2016: Droughts and wildfires in the western U.S. rangelands. Rangelands, $\mathbf{3 8}$, 197-203, https://doi.org/10.1016/j.rala.2016.06.003.

Svoboda, M., and Coauthors, 2002: The Drought Monitor. Bull. Amer. Meteor. Soc., 83, 1181-1190, https://doi.org/10.1175/ 1520-0477-83.8.1181.

USDA, 2015a: Weekly crop progress report, 28 September 2015. USDA Doc., 15 pp., accessed 7 July 2018, https://www.nass. usda.gov/Publications/National_Crop_Progress/.

- 2015b: Weekly crop progress report, 19 October 2015. USDA Doc., 13 pp., accessed 7 July 2018, https://www.nass.usda.gov/ Publications/National_Crop_Progress/.

Wei, H., Y. Xia, K. E. Mitchell, and M. B. Ek, 2013: Improvement of the Noah land surface model for warm season processes: Evaluation of water and energy flux simulation. Hydrol. Processes, 27, 297-303, https://doi.org/10.1002/hyp.9214.

Xia, Y., M. B. Ek, H. Wei, and J. Meng, 2012a: Comparative analysis of relationships between NLDAS-2 forcings and model outputs. Hydrol. Processes, 26, 467-474, https://doi.org/ 10.1002/hyp.8240.

_ - and Coauthors, 2012b: Continental-scale water and energy flux analysis and validation of the North American Land Data Assimilation System project phase 2 (NLDAS-2): 1. Intercomparison and application of model products. J. Geophys. Res., 117, D03109, https://doi.org/10.1029/ 2011JD016048.

, J. Sheffield, M. B. Ek, J. Dong, N. Chaney, H. Wei, J. Meng, and E. F. Wood, 2014: Evaluation of multi-model simulated soil moisture in NLDAS-2. J. Hydrol., 512, 107-125, https:// doi.org/10.1016/j.jhydrol.2014.02.027. 